\title{
LETTERS
}

\section{Opioids for chronic pain}

Some patients with chronic pain are suffering from considerable anxiety and increased pain because their doctors are lowering their use of opioids against their will (www.cbc.ca/news/canada/calgary/chronic -pain-patients-suffering-doctors-opioid -prescribing-1.4495045; https://omny.fm/ shows/roy-green-show/hour-1-segment-1-dr -mary-redmond). This situation has come about because of the concern that opioidrelated deaths among users of illicit drugs are increasing. As a consequence, the Michael G. DeGroote National Pain Centre at McMaster University revised the prescribing guidelines for opioids at the request of Health Canada, and substantially reduced the maximum daily recommended dose. ${ }^{1}$

In 2012, earlier on in the ongoing discussions on opioid use, Dr. B. Eliot Cole, writing in MD Magazine, wondered, "If an individual patient has no problems associated with the use of 120,180 or $240 \mathrm{mg}$ of morphine equivalent on a daily basis, why do we need to reduce that dose? If an individual patient is functioning well with opioid therapy after 90 days, and there is no better treatment available, why would we stop treatment and inflict worsening pain?"2

In his commentary "Rethinking 'Doing Well' on Chronic Opioid Therapy," Dr. David Juurlink begins by stating that there is little evidence that opioids help with chronic pain. ${ }^{3}$ However, a 2010 Cochrane review with 4893 participants found significant reductions in pain with use of opioids. ${ }^{4}$ The review also found that opioid addiction was rare. This study was not cited in the guideline. The Lancet recently released a review on the inadequate use of opioids for pain and said that many worldwide are suffering needlessly and dying in extreme pain. ${ }^{5}$

Addiction specialist Dr. Sally Satel recently wrote, "Much of the conventional wisdom surrounding the opioid crisis holds that virtually anyone is at risk for opioid abuse or addiction ... This is inaccurate." ${ }^{6}$ Halifax pain specialist Dr. Mary Lynch said the same, and stated that studies show that of the thousands of people who have been prescribed opioids for postsurgery or trauma, less than $1 \%$ were still using it a year later. ${ }^{7}$

Dr. Juurlink said in his CMAJ podcast that a patient may be taking a high dose of opioids, have a good quality of life and even be working, and an objective observer may say everything is fine, but the patient may, in fact, not be fine.

The patient may not know that he or she is in trouble, the prescribing doctor may not know, but Dr. Juurlink suggests that the patient may still be in trouble because hyperalgesia might be at play. It well might be, but if it is, the patient will be increasing his or her dose with little benefit. The concept of hyperalgesia, however, is controversial and the jury is still out on this for humans.

In a study of sustained-release morphine for treatment of chronic nonradicular low-back pain, Chu and colleagues found that "the morphine-treated patients developed tolerance to the analgesic effects of remifentanil, but did not develop opioidinduced hyperalgesia. [They] experienced clinically relevant improvements in pain relief, as shown by a $44 \%$ reduction in average visual analogue scale pain levels and a $31 \%$ improvement in functional ability."

Yi and Pryzbylkowski ${ }^{9}$ point out that the exact mechanisms of opioid-induced hyperalgesia are not clearly understood, and further research is required to broaden and develop our knowledge of this topic.

Cutting off patients experiencing pain because of a theoretical construct or because addicts overdose is cruel. The patients who contact me are frightened and in considerable pain because of what their doctors are doing to them, and this should not happen. Many of them, according to a report by the CBC News (www.cbc.ca/news/ canada/british-columbia/pain-medication -opioid-addiction-lorna-bird-1.4177594), are going to drug dealers. The United Nations Single Convention on Narcotic Drugs, ${ }^{10}$ which Canada signed, guarantees the right to narcotic pain medication to people. Our policies violate that international treaty.
I have no doubt that the members of the committee at the Michael G. DeGroote National Pain Centre at McMaster University had the best of intentions and wish to see better patient outcomes. Sadly, the best of intentions often lead to unintended consequences, and that is what we are seeing today. The time has come to rethink and redo the guideline.

\section{Marvin Ross MA}

Medical Writer and Publisher, and President, Bridgeross Communications, Dundas, Ont.

Cite as: CMAJ 2018 March 5;190:E269. doi: 10.1503/cmaj.68954

\section{References}

1. Busse JW, Craigie S, Juurlink DN, et al. Guideline for opioid therapy and chronic noncancer pain. CMAJ 2017;189:E659-66.

2. Cole BE. Just how responsible is PROP? MD Magazine 2012 Dec. 11.

3. Juurlink DN. Rethinking "doing well" on chronic opioid therapy. CMAJ 2017;189:E1222-3.

4. Noble M, Treadwell JR, Tregear SJ, et al. Long-term opioid management for chronic noncancer pain. Cochrane Rev Syst Rev 2010(1)CD006605.

5. Knaul FM, Farmer PE, Krakauer EL, et al.; Lancet Commission on Palliative Care and Pain Relief Study Group. Alleviating the access abyss in palliative care and pain relief - an imperative of universal health coverage: the Lancet Commission report. Lancet 2017;Oct 11. pii: S0140-6736(17)32513-8. [Epub ahead of print]

6. Satel S. Taking on the scourge of opioids. National Affairs [Washington (DC)] Summer 2017.

7. Lynch M. The puzzle of pain: opioids are killing some, but saving others [radio interview]. CBC Quirks and Quarks 2017 May 20.

8. Chu LF, D’Arcy N, Brady C, et al. Analgesic tolerance without demonstrable opioid-induced hyperalgesia: a double-blinded, randomized, placebocontrolled trial of sustained-release morphine for treatment of chronic nonradicular low-back pain Pain 2012;153:1583-92.

9. Yi P, Pryzbylkowski P. Opioid induced hyperalgesia. Pain Med 2015;16:S32-6.

10. Single Convention on Narcotic Drugs, 1961. United Nations; 1961. Available: www.unodc. org/pdf/convention_1961_en.pdf (accessed 2018 Feb. 12).

Competing interests: Marvin Ross is a medical writer who has written on the effects of tapering opioids in the popular press. 